OPEN ACCESS

Edited by:

Geert Wiegertjes,

Wageningen University \& Research,

Netherlands

Reviewed by:

Mark D. Fast,

University of Prince Edward Island,

Canada

Tomáš Korytáŕ,

University of South Bohemia, Czechia

*Correspondence:

Sebastián Reyes-Cerpa

sebastian.reyes@umayor.cl

tThese authors have contributed equally to this work

Specialty section

This article was submitted to

Comparative Immunology,

a section of the journal

Frontiers in Immunology

Received: 16 October 2018

Accepted: 19 February 2019

Published: 19 March 2019

Citation:

Pérez-Stuardo D, Morales-Reyes J,

Tapia S, Ahumada DE, Espinoza A,

Soto-Herrera V, Brianson B, Ibaceta V,

Sandino AM, Spencer $E$,

Vallejos-Vidal E, Reyes-López FE, Valdés J and Reyes-Cerpa S (2019)

Non-lysosomal Activation in

Macrophages of Atlantic Salmon (Salmo salar) After Infection With

Piscirickettsia salmonis.

Front. Immunol. 10:434.

doi: 10.3389/fimmu.2019.00434

\section{Non-lysosomal Activation in Macrophages of Atlantic Salmon (Salmo salar) After Infection With Piscirickettsia salmonis}

\author{
Diego Pérez-Stuardo ${ }^{1 \dagger}$, Jonathan Morales-Reyes ${ }^{2 \dagger}$, Sebastián Tapia ${ }^{1}$, \\ Diego E. Ahumada ${ }^{1}$, Allison Espinoza ${ }^{1}$, Valentina Soto-Herrera ${ }^{3}$, Bernardo Brianson ${ }^{1}$, \\ Valentina Ibaceta ${ }^{1}$, Ana M. Sandino ${ }^{2,3}$, Eugenio Spencer ${ }^{2,3}$, Eva Vallejos-Vidal ${ }^{4}$, \\ Felipe E. Reyes-López ${ }^{4}$, Jorge Valdés ${ }^{1}$ and Sebastián Reyes-Cerpa ${ }^{1 *}$ \\ ${ }^{1}$ Centro de Genómica y Bioinformática, Facultad de Ciencias, Universidad Mayor, Santiago, Chile, ${ }^{2}$ Consorcio de Sanidad \\ Acuícola, Ictio Biotechnologies S.A., Santiago, Chile, ${ }^{3}$ Centro de Biotecnología Acuícola, Universidad de Santiago de Chile, \\ Santiago, Chile, ${ }^{4}$ Department of Cell Biology, Physiology and Immunology, Universitat Autonoma de Barcelona, \\ Barcelona, Spain
}

Piscirickettsia salmonis is a facultative intracellular pathogen and etiological agent of the systemic disease salmonid rickettsial septicemia. It has been suggested that $P$. salmonis is able to survive in host macrophages, localized within a vacuole like-compartment which prevents lysosomal degradation. However, the relevant aspects of the pathogenesis of $P$. salmonis as the host modulation that allow its intracellular survival have been poorly characterized. In this study, we evaluated the role of lysosomes in the response to $P$. salmonis infection in macrophage-enriched cell cultures established from Atlantic salmon head kidneys. Bacterial infection was confirmed using confocal microscopy. A gentamicin protection assay was performed to recover intracellular bacteria and the $16 S$ rDNA copy number was quantified through quantitative polymerase chain reaction in order to determine the replication of $P$. salmonis within macrophages. Lysosomal activity in Atlantic salmon macrophage-enriched cell cultures infected with $P$. salmonis was evaluated by analyzing the lysosomal $\mathrm{pH}$ and proteolytic ability through confocal microscopy. The results showed that $P$. salmonis can survive $\geq 120 \mathrm{~h}$ in Atlantic salmon macrophage-enriched cell cultures, accompanied by an increase in the detection of the $16 S$ rDNA copy number/cell. The latter finding suggests that $P$. salmonis also replicates in Atlantic salmon macrophage-enriched cell cultures. Moreover, this bacterial survival and replication appears to be favored by a perturbation of the lysosomal degradation system. We observed a modulation in the total number of lysosomes and lysosomal acidification following infection with $P$. salmonis. Collectively, the results of this study showed that infection of Atlantic salmon macrophages with $P$. salmonis induced limited lysosomal response which may be associated with host immune evasion mechanisms of $P$. salmonis that have not been previously reported.

Keywords: Atlantic salmon (Salmo salar), Piscirickettsiosis, immune evasion mechanisms, macrophages, lysosome, proteolytic activity 


\section{INTRODUCTION}

Piscirickettsia salmonis (P. salmonis) is the etiological agent of the systemic disease termed Piscirickettsiosis or salmonid rickettsial septicemia, which mostly affects salmonid species in saltwater (1), although it has also been identified in freshwater salmonid cultures (2). P. salmonis was first reported in Chile in 1989 as a pathogenic agent in coho salmon (Oncorhynchus kisutch) and characterized as a Gram-negative bacterium, non-motile, unencapsulated, pleomorphic, usually coccoid, with a diameter between 0.2 and $1.5 \mu \mathrm{m}(1,3,4)$. P. salmonis is an intracellular pathogen, classified phylogenetically as a Gammaproteobacteria in the family Piscirickettsiaceae, and is closely related to Legionella, Francisella, and Coxiella (1).

Notably, infection with $P$. salmonis is responsible for high mortality rates only in Chile. In other countries (e.g., Norway, Canada, and Ireland), outbreaks have been reported with limited impact $(5,6)$. In Chile, the management of Piscirickettsiosis is a national priority given its highly aggressive nature, recurring outbreaks, and wide dispersion among other cultivated salmonid species (7-9). In fact, the National Fisheries Service (SERNAPESCA, Servicio Nacional de Pesca) has identified $P$. salmonis as the most serious health concern facing the Chilean salmon industry (10). The SERNAPESCA has established a monitoring and control program to reduce the impact of salmonid rickettsial septicemia (9). Despite the great impact that P. salmonis has had on the aquaculture industry, key aspects of its biology, pathogenesis, and virulence remain poorly understood, significantly hampering the strategies for its control $(11,12)$. It has been reported that once $P$. salmonis has colonized, the host, it survives and replicates in vacuoles of macrophage-like cells that do not merge with lysosomes $(11,13,14)$. Moreover, infection of macrophages with $P$. salmonis induces an anti-inflammatory milieu, probably involved in the development of its bacterial virulence mechanism to ensure replication and survival (15).

Macrophages are part of the first-line cell defense against bacterial infection, specializing in phagocytosis, destruction of foreign microorganism, and presentation of antigens (16, 17). The impact of an infection depends on the balance between the capacity of macrophages to recognize and destroy bacterial pathogens and the ability of pathogens to disrupt the functions of these macrophages (18). Infection of macrophages using different molecular effectors to undermine macrophage signaling is a common strategy adopted by intracellular pathogens to evade the immune system and ensure systemic spread into their hosts. In this way, different bacterial pathogens use diverse strategies to subvert the functions of macrophages. One of the most important strategies is the evasion of phagolysosomal degradation $(11,18)$. Maturation of the phagosome that fuses with lysosomal compartments-containing an acid and hydrolytic lumen with enzymes responsible for the eradication of internalized bacteria-is critically linked to the destruction of pathogenic bacteria $(19,20)$. Therefore, interference with the phagosomal maturation is essential for bacteria to enable their presence and replication within macrophages. Importantly, this pathogen strategy has already been reported in bacteria closely related to $P$. salmonis, including
Legionella pneumophila (L. pneumophila), and Coxiella burnetii (C. burnetii) $(21,22)$.

Gomez et al. (11), described that $P$. salmonis-along with the phylogenetically-related bacteria L. pneumophila or C. burnetiipossess the deficient in organelle trafficking/intracellular multiplication (Dot/Icm) secretion system genes classified as type IVB secretion system (TIVBSS) or an equivalent to achieve a productive infection. The Dot/ $\mathrm{Icm}$ proteins form part of a specialized secretion system encoded by the $d o t / i \mathrm{~cm}$ genes and constitute the major virulence mechanism of L. pneumophila and $C$. burnetii responsible for their intracellular survival and multiplication (23-25). During infection, L. pneumophila evades phagosome-lysosome fusion and phagosome acidification. Although subtly increased, this process is delayed for $\geq 16 \mathrm{~h}$ (26). Moreover, L. pneumophila has the ability to alter the maturation of the endocytic vacuole in which it initially resides, allowing the establishment of an organelle within phagocytic host cells that supports replication (27). Conversely, C. burnetii resides in an acidified lysosome-like compartment, in which it can replicate in the presence of several lysosomal proteins such as v-ATPase (22). To the best of our knowledge, there is limited evidence regarding the lysosomal acidification and functionality of Atlantic salmon macrophages infected with $P$. salmonis. The availability of such evidence may assist in unraveling the host-pathogen interaction mechanisms associated with $P$. salmonis infection.

The aim of this study was to determine whether the lysosomal activity in Atlantic salmon macrophages is modulated by infection with P. salmonis.

\section{MATERIALS AND METHODS}

\section{Experimental Fish}

Atlantic salmon (Salmo salar) with an average weight of $55 \pm$ $15 \mathrm{~g}$ were obtained from a local farm and maintained in tanks with freshwater at a biomass of $10-12 \mathrm{Kg} \mathrm{m}^{-3}$ and controlled temperature $\left(14-16^{\circ} \mathrm{C}\right)$ with continuous aeration. Water quality parameters, such as $\mathrm{pH}$, oxygen, and the levels of nitrogen compounds (i.e., nitrate, nitrite, and ammonia) were monitored daily and maintained at constant values. The fish were fed with commercial pellets twice daily (Golden Optima, Biomar, Puerto Montt, Chile), and acclimatized for $\geq 3$ weeks prior to the experiments. The maintenance of fish was performed in accordance with the ethical standards of the Institutional Ethics Committee of Universidad de Santiago de Chile (approved in internal report $\mathrm{n}^{\circ}$ 364) and the relevant legislation in force.

\section{Isolation of Macrophages and Cell Culture}

Macrophage-enriched cell cultures were obtained from Atlantic salmon head kidneys as described by Braun-Nesje et al. (28) with slight modifications. Briefly, the head kidney of fish was aseptically extracted and disaggregated using a cell strainer (pore size: $70 \mu \mathrm{m})(\mathrm{BD}$ Falcon, Seaton Delaval, England) on a $60 \times$ $15 \mathrm{~mm}$ culture plate (BD Falcon) in the presence of Leibovitz medium (L-15; Hyclone, Thermo Scientific, Massachusetts, USA) supplemented with 2-mercaptoethanol $36 \mu \mathrm{M}$ (2-ME; Gibco, Thermo Scientific), fetal bovine serum 3\% (v/v) (FBS; Hyclone, GE Healthcare Life Sciences, Utah, USA), penicillin 
$200 \mathrm{U} / \mathrm{mL}$, streptomycin $200 \mu \mathrm{g} / \mathrm{mL}$ (Corning, New York, NY, USA), amphotericin B $2.5 \mathrm{mg} / \mathrm{mL}$ (Corning), and sodic heparin 24.7 UI/mL (Leo Pharma, Ballerup, Denmark) (supplement 1). mechanical disaggregation was performed until a homogeneous cell suspension was obtained. The leukocyte fraction was isolated through a discontinuous gradient in densities of $34 \%$ and $51 \%$ of Percoll (GE Healthcare) diluted in miliQ water and Hank's Balanced Salt Solution (HBSS 10X, Gibco). The cell suspension was deposited on the discontinuous Percoll gradient and the column was centrifuged for $40 \mathrm{~min}$ at $400 \mathrm{~g}$ at $16^{\circ} \mathrm{C}$. The leukocyte interface was recovered and resuspended in L-15 medium (supplement 1). To eliminate the traces of Percoll, the cell suspension was centrifuged twice for $7 \mathrm{~min}$ at 250 $g$ at $16^{\circ} \mathrm{C}$. The cell suspension was placed on 12 -well plates at 40,000 cells $/ \mathrm{cm}^{2}$ in L-15 medium supplemented with 2ME $36 \mu \mathrm{M}$, FBS $10 \%$ (v/v) (Hyclone), penicillin $200 \mathrm{U} / \mathrm{mL}$, streptomycin $200 \mu \mathrm{g} / \mathrm{mL}$ (Corning), and amphotericin B 2.5 $\mathrm{mg} / \mathrm{mL}$ (Corning) (supplement 2) at $16^{\circ} \mathrm{C}$. At day 1 , the primary culture was washed with phosphate-buffered saline (PBS) 1X, non-adherent cells were discarded to enrich the monocytic/macrophage adherent population, and cultivated in L-15 medium containing supplement 2. At days 3, 5, and 7, the cultured cells were washed with PBS 1X, the non-adherent cells were discarded, and the medium of the cell cultures was replaced by L-15 medium supplemented with 2-ME $36 \mu \mathrm{M}$ and FBS $10 \%$ (v/v) (Hyclone) (supplement 3).

\section{Cultivation and Propagation of $P$. salmonis}

Culture and propagation of $P$. salmonis (strain 9734, ETECMA, Puerto Montt, Chile) was performed in salmonid cell line CHSE214 (ATCC $\mathrm{N}^{\circ}$ CRL-1682) as previously described by Fryer et al. (29). The CHSE-214 cell line was maintained in minimal essential medium (MEM; Corning) FBS 10\% (v/v) (Hyclone), HEPES buffer $10 \mathrm{mM}$ (Corning), and non-essential amino acids $1 \%(\mathrm{v} / \mathrm{v})$ (Corning) (supplement 4) at $16^{\circ} \mathrm{C}$. The infection was observed through conventional inverted microscopy (Motic AE31E) 4-6 days post-infection (dpi) to determine the cytopathic effect on cells (30). The bacteria were quantified using a Petroff-Hausser chamber (Hausser Scientific, Pennsylvania, USA) according to the instructions provided by the manufacturer.

\section{Inactivation of $\boldsymbol{P}$. salmonis}

$P$. salmonis was extracted from the infection supernatant of CHSE-214 cells with evident cytopathic effect. Cellular debris was eliminated through centrifugation for $5 \mathrm{~min}$ at $500 \mathrm{~g}$. Subsequently, $P$. salmonis was centrifuged for $15 \mathrm{~min}$ at 7,500 $g$ at $16^{\circ} \mathrm{C}$. The pellet was resuspended in $4 \%$ paraformaldehyde (PFA; Sigma Aldrich, Missouri, USA) diluted in PBS $1 \mathrm{X}$ and incubated overnight at $4^{\circ} \mathrm{C}$. Finally, the bacterial suspension was centrifuged for $15 \mathrm{~min}$ at $7,500 \mathrm{~g}$ at $16^{\circ} \mathrm{C}$, the supernatant was discarded, and the pellet was resuspended in L-15 medium containing supplement 3 .

\section{Detection of $P$. salmonis Using Quantitative Polymerase Chain Reaction (qPCR)}

The gene encoding for 16S rRNA (Fw: 5' -AGG-GAG-ACT-GCCGGT-GAT-A-3'; Rv: 5'-ACT-ACG-AGG-CGC-TTT-CTC-A-3') was amplified as described by Karatas et al. to detect the presence of P. salmonis in the infected cell cultures (31). Genomic DNA was obtained using the Wizard ${ }^{\mathrm{TM}}$ Genomic DNA Purification kit according to the instructions provided by the manufacturer. The PCR amplification was performed using the PowerUp ${ }^{T M}$ SYBR $^{\circledR}$ Green master Mix (Thermo Scientific) according to the instructions provided by the manufacturer. The primers were added to a final concentration of $0.4 \mu \mathrm{M}$, and $12 \mathrm{ng}$ of template were used. The qPCR was performed on a QuantStudio 3 RealTime PCR system (Thermo Scientific). The quantification of $16 \mathrm{~S}$ rDNA copies was determined through interpolation from the standard curve with the cycle threshold $(\mathrm{Ct})$ value obtained for each sample. The results are expressed as $16 \mathrm{~S} \mathrm{rDNA}$ copy/cell.

\section{Fluorescein Isothiocyanate (FITC) Staining for $P$. salmonis}

In order to monitor the P. salmonis infection into macrophageenriched cell cultures, we stained the bacteria using FITC (Thermo Scientific). P. salmonis was extracted from the infection supernatant of CHSE-214 cells with evident cytopathic effect and centrifuged for $15 \mathrm{~min}$ at $7,500 \mathrm{~g}$ at $16^{\circ} \mathrm{C}$. Subsequently, the bacteria were incubated for $30 \mathrm{~min}$ with FITC $100 \mu \mathrm{g} / \mathrm{mL}$ diluted in L-15 medium without supplement. Finally, the bacteria were centrifuged for $15 \mathrm{~min}$ at $7,500 \mathrm{~g}$ at $16^{\circ} \mathrm{C}$ and resuspended in L15 medium without supplement. The viability of $P$. salmonis was determined by comparison of bacterial growth in enriched blood agar plates (32) with non-stained P. salmonis (Figure 1). Growth of bacterial colonies was analyzed for the specific detection of $16 \mathrm{~S}$ rDNA using real time PCR (31) and morphology as previously described by Mauel et al. (32).

\section{P. salmonis Infection}

Macrophage-enriched cell cultures from Atlantic salmon head kidneys were incubated for $30 \mathrm{~min}$ with $10 \mu \mathrm{M}$ Cell Tracker Red (CMPTX; Thermo Scientific) diluted in L-15 without supplements. Subsequently, the cells were washed thrice with PBS $1 \mathrm{X}$ and incubated with $P$. salmonis-FITC stained at a multiplicity of infection (MOI) of 0.5 bacteria/cell (previously quantified using a Petroff-Hausser chamber), and cultured in L-15 medium containing supplement 3 . Cells were incubated for 24 and $120 \mathrm{~h}$ post-infection (hpi). Subsequently, the cell culture was fixed with 4\% PFA for $10 \mathrm{~min}$ and washed thrice with PBS 1X. The nucleus was stained with 4',6-diamidino-2-phenylindole, dihydrochloride (DAPI) $0.1 \mu \mathrm{g} / \mathrm{mL}$ for $1 \mathrm{~min}$ and the cells were washed twice with PBS 1X and once with MiliQ water to wash the residuary salts. Subsequently, the cells were mounted on slides using the mounting solution Fluoromount ${ }^{\mathrm{TM}}$ (Thermo Scientific). Micrographs were obtained using a confocal microscope Zeiss LSM 710, the images were processed and analyzed using the Fiji software (33).

\section{Gentamicin Protection Assay}

In order to recover the intracellular bacterium from the infected macrophage-enriched cell cultures, a gentamicin protection assay was performed. Briefly, macrophage-enriched cell cultures were infected with $P$. salmonis at a MOI of 10 bacteria/cell for 

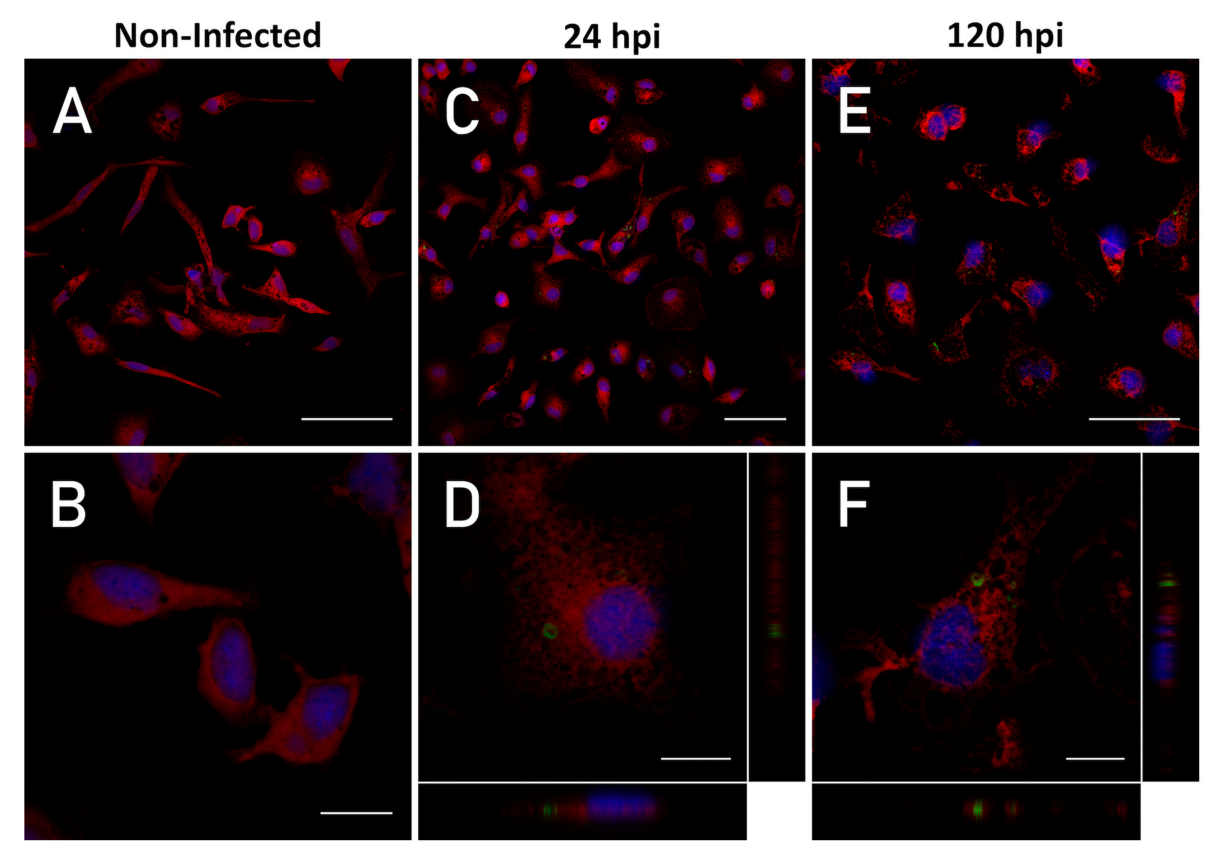

FIGURE 1 | Intracellular detection of $P$. salmonis. Macrophage-enriched cultures obtained from Atlantic salmon head kidneys were incubated with $P$. salmonis-FITC at a MOI of 0.5 bacteria/cell for 24 and 120 hpi in L-15 supplemented medium. The cellular nucleus (stained with DAPI; blue), cell cytoplasm (stained with CMPTX; red), and $P$. salmonis-FITC (green) are represented. The intracellular location of $P$. salmonis-FITC was determined by confocal microscope orthogonal image analysis from the z-stack obtained. (A,B) Non-infected macrophages (scale bar 50 and $10 \mu \mathrm{m}$, respectively). (C,D) Macrophages at 24 hpi (scale bar 50 and $10 \mu \mathrm{m}$, respectively). (E,F) Macrophages at $120 \mathrm{hpi}$ (scale bar 50 and $10 \mu \mathrm{m}$, respectively).

24 and 120 h. Recovery of the intracellular bacterium was performed following the protocol described by Rodriguez et al. (34) Imarai et al. (35), and Fast et al. (36), with modifications. Macrophage-enriched cell cultures infected with $P$. salmonis were incubated with gentamicin $(100 \mu \mathrm{g} / \mathrm{mL})$ for $60 \mathrm{~min}$ to eliminate bacteria from the extracellular environment. After 35 washes with cold PBS 1X, saponin (Sigma) was added (1\% $\mathrm{p} / \mathrm{v}$ in $\mathrm{PBS} 1 \mathrm{X}$ ) for $15 \mathrm{~min}$ at $16^{\circ} \mathrm{C}$ to permeabilize the cells. Finally, the homogenized cells were diluted in PBS $1 \mathrm{X}$ and centrifuged at $6,000 \mathrm{~g}$ for $10 \mathrm{~min}$ at $4^{\circ} \mathrm{C}$. The supernatant was discarded and the pellet was resuspended in $100 \mu \mathrm{L}$ of PBS 1X. Genomic DNA from the homogenized cells was extracted using the Wizard ${ }^{\mathrm{TM}}$ Genomic DNA Purification kit according to the instructions provided by the manufacturer. Quantification of intracellular $P$. salmonis recovered from head kidney cell cultures was performed through specific qPCR absolute quantification using the set of primers described by Karatas et al. (31). The supernatant used for the gentamicin treatment as well as the PBS used for each wash were recovered and subsequently centrifuged at $6,000 \mathrm{~g}$ for $10 \mathrm{~min}$ at $4^{\circ} \mathrm{C}$ to eliminate any viable extracellular bacteria after treatment with gentamicin or the subsequent washes. This process was performed to prevent an overestimation of the intracellular bacteria. The obtained pellets were resuspended in $100 \mu \mathrm{L}$ PBS. Part of these suspensions (50 $\mu \mathrm{L}$ ) was plated in $\mathrm{CHAB}$ agar and cultivated by 14 days at $20^{\circ} \mathrm{C}$. The remaining $50 \mu \mathrm{L}$ were used to extract genomic DNA for the qPCR amplification of $16 \mathrm{~S}$ rDNA with the same specific primers mentioned above.

\section{Evaluation of Lysosomal Acidification}

Evaluation of lysosomal acidification in P. salmonis-infected macrophage-enriched cell cultures was performed by fluorescence analysis using the LysoSensor ${ }^{\mathrm{TM}}$ Yellow/Blue probe (LSYB; Thermo Scientific). This ratiometric probe can be used to measure the $\mathrm{pH}$ of acidic organelles. The LysoSensor ${ }^{\mathrm{TM}}$ dye produces blue and yellow fluorescence in neutral and acidic environments, respectively. Therefore, a fluorescence shift from blue (maximum emission at $430 \mathrm{~nm}$ ) to yellow (maximum emission at $535 \mathrm{~nm}$ ) indicates an increase in lysosomal $\mathrm{pH}$ (37).

The macrophage-enriched cell cultures were established in 12 well plates with glass coverslips and infected with $P$. salmonis at a MOI of 10 bacteria/cell for $1 \mathrm{~h}$ in L-15 medium containing supplement 3. After incubation, the cell cultures were washed once with PBS $1 \mathrm{X}$ and incubated with L-15 containing supplement 3. In order to determine the short-term effect on lysosomal acidification in P. salmonis-infected macrophageenriched cell cultures, a lysosomal acidification analysis was performed at 3, 6, and 24 hpi. A non-infected and an incubation with inactivated $P$. salmonis conditions were simultaneously performed as internal experimental controls. At each time point, the infected cells were incubated with LSYB $10 \mu \mathrm{M}$ for $5 \mathrm{~min}$. Subsequently, the cells were washed thrice with PBS $1 \mathrm{X}$ and fixed with 4\% PFA (p/v) (Sigma Aldrich) for $10 \mathrm{~min}$, followed by three additional washes with PBS 1x. Finally, the nucleus was stained with propidium iodide (PI) $1 \mu \mathrm{g} / \mathrm{mL}$ (incubation for $1 \mathrm{~min}$ ) and the cells were washed twice with PBS $1 \mathrm{X}$ and once with MiliQ water to remove the residuary salts. The samples were 
mounted on slides with Fluoromount ${ }^{\mathrm{TM}}$ (Sigma Aldrich) and the images were obtained using a Leica SP8 confocal microscope (Leica, Wetzlar, Germany). Results were obtained by the division of the emission spectrum of the LSYB probe, specifically to obtain an acidic indicator channel (acquired between 500 and $580 \mathrm{~nm}$ ) and a neutral-basic indicator channel (acquired between 450 and $495 \mathrm{~nm}$ ). According to instructions provided by the manufacturer, the fluorescence intensity obtained in the acidic indicator channel had to be $\geq 2$-fold than that obtained in the neutral-basic indicator channel to consider a lysosome as acidic. The analysis of lysosomal acidity was performed using the software LAS X (version 3.3.0). Briefly, the fluorescence histogram intensity for each indicator channel was obtained for each lysosome in the samples, and the fluorescence intensity average per count value was calculated using the software. Subsequently, the ratio between the values obtained from the two indicator channels was used as the acidity index. An acidic index $\geq 2$ denoted an acidic $\mathrm{pH}$. Conversely, an acidity index $0<\mathrm{x}<2$ denoted neutral-basic $\mathrm{pH}$. The number of lysosomes per sample was normalized to the number of cells per sample. For each condition, four random micrographs with a $z$-stack containing on average 30 cells were obtained. Every lysosome present in the micrograph was analyzed based on the region of interest selected using the software. The micrographs were processed through the software Fiji (33). The results are represented as the number of lysosomes/cell and percentage of acidic lysosomes per condition.

\section{Evaluation of Lysosomal Activity}

In order to determine the short-term effect on the lysosomal activity in $P$. salmonis-infected macrophage-enriched cell cultures, a fluorescence analysis using the $\mathrm{DQ}^{\mathrm{TM}}$ Green BSA probe was performed. This probe is composed of albumin derivatized with a self-quenching fluorochrome. The degradation of $\mathrm{DQ}^{\mathrm{TM}}$ Green BSA in acidic lysosomes results in smaller protein fragments than those of isolated fluorophores. Once the quencher is released, brightly fluorescent products are observed. The cleavage of $\mathrm{DQ}^{\mathrm{TM}}$ Green BSA results in the release of fragments with maximum excitation and emission at 505 and $515 \mathrm{~nm}$, respectively (38-40).

The macrophage-enriched cell cultures were established in 12well plates with glass coverslips and infected with $P$. salmonis on a MOI of 10 bacteria/cell for $1 \mathrm{~h}$ in L-15 medium containing supplement 3. After the incubation, the cell cultures were washed once with PBS $1 \mathrm{X}$ and incubated with L-15 containing supplement 3. Subsequently, an analysis of lysosomal activity was performed at 3,6 , and 24 hpi with $P$. salmonis. A noninfected and an incubation with inactivated $P$. salmonis were simultaneously performed as internal experimental controls. Two $\mathrm{h}$ prior to reaching each time point (i.e., 3, 6, and 24 hpi), DQ ${ }^{\mathrm{TM}}$ Green BSA $10 \mu \mathrm{g} / \mathrm{mL}$ in L-15 medium containing supplement 3 was added to the infected cells. Subsequently, the cells were washed thrice with PBS 1X and fixed using 4\% PFA. The nuclei were stained with PI $1 \mu \mathrm{g} / \mathrm{mL}$ as previously described. The samples were mounted on slides using the mounting solution Fluoromount ${ }^{\mathrm{TM}}$ (Thermo Scientific). The micrographs were obtained using a Leica SP 8 confocal microscope (Leica), and processed and analyzed using the Fiji software (33). The analysis was performed by obtaining four micrographs with a $z$-stack to determine the total amount of hydrolytic events per cell that contains in average 30 cells on the micrographs, for each experimental condition and counting every positive event to the fluorescence of $\mathrm{DQ}^{\mathrm{TM}}$ Green BSA. The data were normalized to the number of cells on the micrograph and the results are represented as the number of proteolytic events/cell.

\section{Statistical Analysis}

Statistical differences in the quantification of $P$. salmonis recovered from macrophage-enriched cell cultures were determined using the one-tailed Mann-Whitney $U$ test. Statistical differences in proteolytic events between the groups analyzed were determined using two-way analysis of variance (ANOVA) with a Dunnett's multiple comparison test. We used the GraphPad Prism v6.0 for Windows software (GraphPad Software Inc.) to calculate the mean and the standard error of the mean (SEM) and perform the statistical tests. A $p<0.05$ denoted statistical significance.

\section{RESULTS}

\section{$P$. salmonis Infects Macrophage-Enriched Cell Cultures Obtained From Atlantic Salmon Head Kidneys}

Our first aim was to demonstrate that the bacteria invade the immune system, reside, and replicate in macrophageenriched cell cultures obtained from Atlantic salmon head kidney infected with $P$. salmonis. To detect and visualize $P$. salmonis in the macrophages, the cells were infected with FITC-labeled $P$. salmonis. The simultaneous detection of $P$. salmonis-FITC red-stained cytoplasm and DAPI-stained nucleus on 1.16- $\mu \mathrm{m}$ thickness cross-sectional images by confocal microscopy showed that, after 24 and $120 \mathrm{~h}$ of incubation, bacteria were found in the cytoplasm of macrophages. An orthogonal view of the cells (midplane z section; height: $1.3 \mu \mathrm{m}$ ) confirmed the intracellular localization of $P$. salmonis (Figure 1). Previously, the viability (growth and morphology) of $P$. salmonis-FITC was compared with that observed in non-stained $P$. salmonis. Both bacteria were seeded in enriched-blood agar and-after 10 days of incubationsmall single $(0.1 \mathrm{~mm})$ circular, entire, white, and convex colonies of $P$. salmonis were visible. Single colonies were selected and specific real time PCR was performed. This analysis yielded a positive detection of $16 \mathrm{~S} \mathrm{rDNA}$ of $P$. salmonis with a unique amplification product (Supplementary Figure 1).

In the gentamicin protection assay, the quantification of intracellular bacteria recovered from macrophage-enriched cell cultures reflects a two magnitude orders significant increase in the $16 \mathrm{~S} \mathrm{rDNA}$ copy number/cell between 24 and $120 \mathrm{hpi}$ (Figure 2). The results indicated that $P$. salmonis is able to infect macrophages after $24 \mathrm{hpi}$, as well as survive and replicate in macrophage-enriched cell cultures after $120 \mathrm{hpi}$. This evidence suggests that $P$. salmonis may modify the mechanisms associated with pathogen eradication, thus enabling the localization and replication in macrophages. 


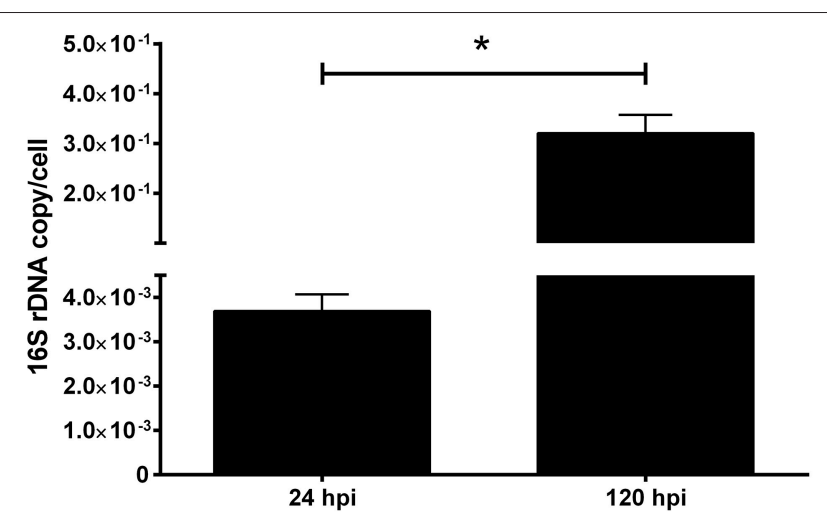

FIGURE 2 | $16 \mathrm{~S}$ rDNA quantification of $P$. salmonis infecting macrophage-enriched cell cultures. Macrophage-enriched cultures obtained from Atlantic salmon head kidneys were incubated with $P$. salmonis-FITC at a $\mathrm{MOI}$ of 0.5 bacteria/cell in $\mathrm{L}-15$ supplemented medium. The coding gene of the ribosomal $16 \mathrm{~S}$ subunit was quantified at 24 and $120 \mathrm{hpi}$ to indirectly evaluate the bacterial proliferation. The data (mean \pm SEM) were normalized to the number of cells per sample. The statistical analysis was performed using Student's t-test with a Mann-Whitney post-statistical test. Significant difference: ${ }^{*} p<0.05$.

\section{Lysosomal Acidification Is Affected in $P$. salmonis-Infected Macrophage-Enriched Cell Cultures}

We evaluated the lysosomal acidification of macrophages to determine whether infection with $P$. salmonis favors the modification of the mechanisms associated with pathogen eradication in the first hpi. For this purpose, we incubated macrophage-enriched cell cultures with $P$. salmonis for $1 \mathrm{~h}$.

The confocal microscopy images showed the presence of vesicles with a degree of acidity (Figures 3A-C) in non-infected cells at all time points analyzed-detected by a punctate pattern of yellow/green fluorescence. Blue fluorescence dots were also observed, suggesting the presence of vesicles with a neutral $\mathrm{pH}$. Analysis of the fluorescence emission in P. salmonis-infected macrophage-enriched cell cultures showed that, at 3 and 6 hpi, a marginal or no increase was observed in the number of punctate patterns of yellow/green fluorescence compared with that identified in non-infected cells (Figures 3D,E). An increase in the number of punctate patterns of yellow/green fluorescence was observed only at 24 hpi (Figure 3F) vs. that observed for the non-infected macrophage-enriched cell cultures (Figure 3C). These results were corroborated by the quantification of the number of lysosomes/cells in macrophageenriched cell cultures infected with $P$. salmonis. This analysis showed a slight increase in number compared with that recorded for the non-infected cells at $3 \mathrm{hpi}$, which only got a significant increase at $24 \mathrm{hpi}$ (15 lysosomes/cell) compared to $3 \mathrm{hpi}$ with P. salmonis (6 lysosomes/cell) (Figure 3J). Conversely, following the incubation of macrophage-enriched cell cultures with inactivated $P$. salmonis, the number of punctate patterns of yellow/green fluorescence increased at 3, 6, and $24 \mathrm{hpi}$ (Figures 3G-I) compared with those recorded for non-infected cells (Figures 3A-C) and for those infected with live P. salmonis (Figures 3D-F). These results suggest an increase in the number of acidic vesicles against inactivated $P$. salmonis, but not against live P. salmonis.

Subsequently, we determined the percentage of acidic lysosomes in macrophage-enriched cell cultures infected with P. salmonis. Despite the slight increase observed in the number of lysosomes at $3 \mathrm{hpi}$, we detected a significant increase in the percentage of acidic lysosomes (Figure 3K). However, the percentage of lysosomes with an acidic $\mathrm{pH}$ in macrophageenriched cell cultures infected with $P$. salmonis decreased with longer infection times (i.e., 6 and $24 \mathrm{hpi}$ ) (Figure 3K), despite the higher number of lysosomes/cell observed at 24 hpi (Figure 3J). Conversely, following the incubation of macrophage-enriched cell cultures with inactivated P. salmonis, the percentage of acidic lysosomes increased to approximately $80 \%$ of all lysosomes evaluated after $3 \mathrm{~h}$ post-incubation. This increase was significantly different compared with that observed in non-infected cells and slightly superior to that observed in macrophage-enriched cell cultures infected with P. salmonis (Figure 3K). The results obtained at 6 and $24 \mathrm{~h}$ post-incubation were similar, with approximately $70 \%$ acidic lysosomes observed in the samples. This finding represents a significant increase compared with the values obtained for non-infected cells and macrophage-enriched cell cultures infected with P. salmonis (Figure 3K). These results indicate that lysosomes are not acidified following the infection of macrophage-enriched cell cultures with $P$. salmonis. Conversely, following the incubation of macrophage-enriched cell cultures with inactivated $P$. salmonis, there is an increase in the percentage of acidic lysosomes along with an increase in the number of lysosomes/cell. This finding suggests that lysosomal activation in macrophage-enriched cell cultures occurs after an appropriate stimulus.

\section{Infection With $P$. salmonis Diminishes the Hydrolytic Activity in Macrophage-Enriched Cell Cultures}

One of the key steps in pathogen eradication is the proteolytic activity of phagocytes. Thus, the proteolytic activity of macrophages was evaluated to determine whether infection with $P$. salmonis modifies the cell host proteolytic activity in the first hpi as a mechanism of immune evasion. The proteolytic activity was assessed using the fluorescent degradative event marker $\mathrm{DQ}^{\mathrm{TM}}$ Green BSA. According to the results, noninfected macrophage-enriched cell cultures exhibited a low number of fluorescent events at all time points (Figures 4A-C). Interestingly, following the infection of macrophag e-enriched cell cultures with P. salmonis, a similar pattern in fluorescence emission from proteolytic events/cell was observed vs. that reported in non-infected cells at all time points (Figures 4D-F). Conversely, following the incubation of macrophage-enriched cell cultures with inactivated $P$. salmonis for $3 \mathrm{~h}$, we observed a greater number of punctate patterns of intense green fluorescence (Figure 4G) vs. that observed in non-infected cells. Similar results were observed at 6 and $24 \mathrm{hpi}$, with proteolytic 

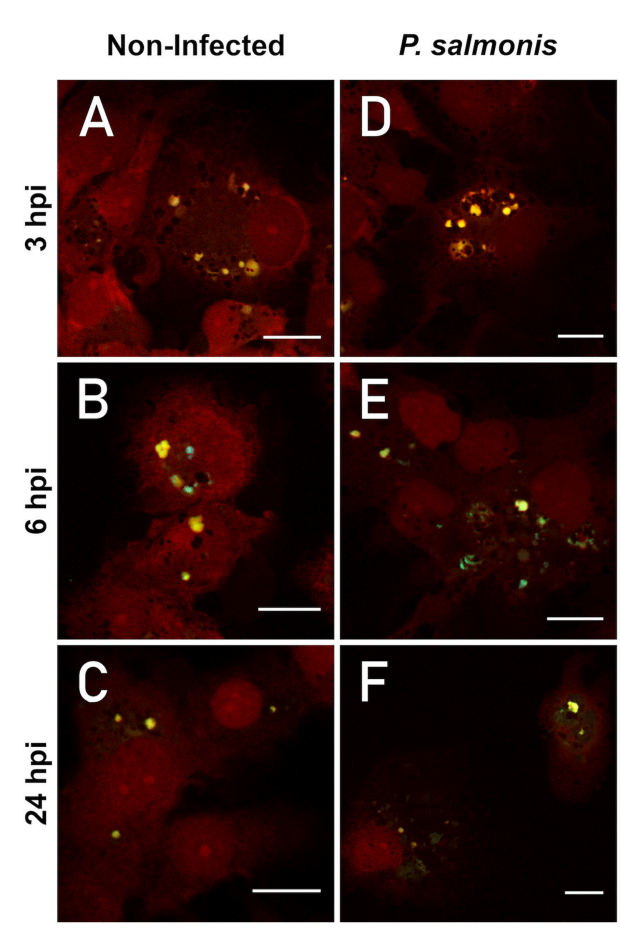

\section{Inactivated} $P$. salmonis
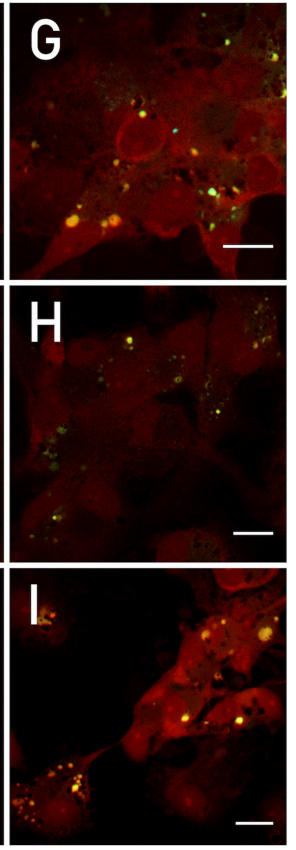
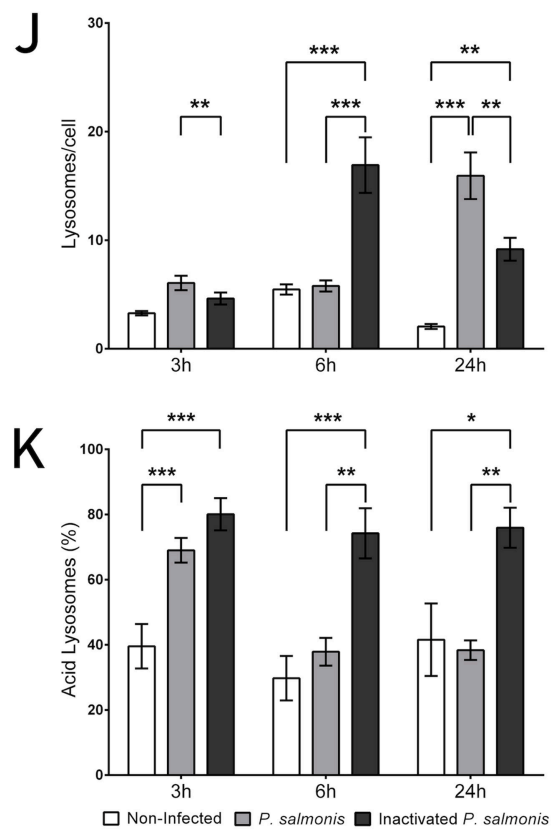

FIGURE 3 | Lysosomal acidification in macrophage-enriched cell cultures infected with $P$. salmonis. Macrophage-enriched cultures obtained from Atlantic salmon head kidneys were incubated with $P$. salmonis at a MOl of 10 bacteria/cell and analyzed at 3, 6, and 24 hpi. The macrophage-enriched cell culture was treated with the LSYB probe (green and blue) to stain lysosomes and analyze their pH. The nucleus was stained with PI (red). (A-C) Non-infected macrophages analyzed at 3, 6, and $24 \mathrm{~h}$. Macrophages-enriched cell culture incubated with $P$. salmonis for $3 \mathrm{~h}$ (D), $6 \mathrm{~h}$ (E), and $24 \mathrm{~h}$ (F). Macrophage-enriched cell culture incubated with inactivated P. salmonis for $3 \mathrm{~h}(\mathbf{G}), 6 \mathrm{~h}(\mathbf{H})$, and $24 \mathrm{~h} \mathbf{( I )}$. Scale bar: $10 \mu \mathrm{m}(\mathbf{J}, \mathbf{K})$. Lysosomal quantification in macrophage-enriched cell cultures infected with $P$. salmonis. Macrophage-enriched cell culture was infected with $P$. salmonis at a $\mathrm{MOI}$ of 10 bacteria/cell and analyzed at 3, 6, and 24 hpi. The lysosomes were stained with the LSYB probe and quantified as acidic lysosomes or neutral-basic (NB) lysosomes. The data were normalized to the number of cells analyzed. Non-infected macrophage-enriched cell culture and incubation with inactivated $P$. salmonis were used as controls for each time point. (J) Total number of lysosomes per cell. (K) Percentage of acidic lysosomes for each condition. The statistical analysis was performed through parametric ANOVA with a Dunnett's multiple comparison test. Significant differences: ${ }^{\star} p<0.05,{ }^{* *} p<0.01,{ }^{* * *} p<0.001$.

events reported by intense fluorescence events (Figures $4 \mathbf{H}-\mathbf{I}$ ). At both time points, greater numbers of events were observed vs. those reported in non-infected cells and macrophage-enriched cell cultures infected with $P$. salmonis.

In order to assess whether $P$. salmonis affects the proteolytic activity of macrophage-enriched cell cultures, we quantified the fluorescent events using confocal microscopy (Figure 4J). At 3 hpi, we observed a non-significant decrease in the number of proteolytic events/cell compared with that reported in non-infected cells (22 vs. 35 proteolytic events/cell, respectively) (Figure 4J). Similar results were observed at 6 and 24 hpi with P. salmonis; however, the differences were not significant (Figure 4J). Conversely, following the incubation of macrophage-enriched cell cultures with inactivated $P$. salmonis, we observed a significant increase in the number of proteolytic events/cell compared with that reported in non-infected cells at all time points, reaching 60 proteolytic events/cell at 24 hpi (Figure 4J). Collectively, these results suggest an inactivation of lysosomal activity following the infection of macrophage-enriched cell cultures with $P$. salmonis.

\section{DISCUSSION}

In this study, we demonstrated that $P$. salmonis is able to survive, replicate, and perturb lysosomal activation in infected macrophage-enriched cell cultures. This evasion mechanism associated to phagosomal maturation has been previously reported in bacteria closely related to $P$. salmonis, including $L$. pneumophila and C. burnetii $(21,22)$.

The lysosome is the major degradative compartment of eukaryotic cells. It is a membrane-bound compartment specialized in the degradation and recycling of cellular components. In addition, it has an internal acidic $\mathrm{pH}$ that provides an optimal environment for the function of hydrolases, thus facilitating the degradation of macromolecules (41). Multiple endocytic pathways, such as phagocytosis, macropynocitosis, clathrin- and caveolin-dependent and independent endocytosis, import macromolecules from extracellular environment and from the cell's own limiting membrane to be degraded via the lysosomal system. Moreover, the self-catabolic process-known as autophagy-allows the capture and delivery of cytoplasmic macromolecules (i.e., 

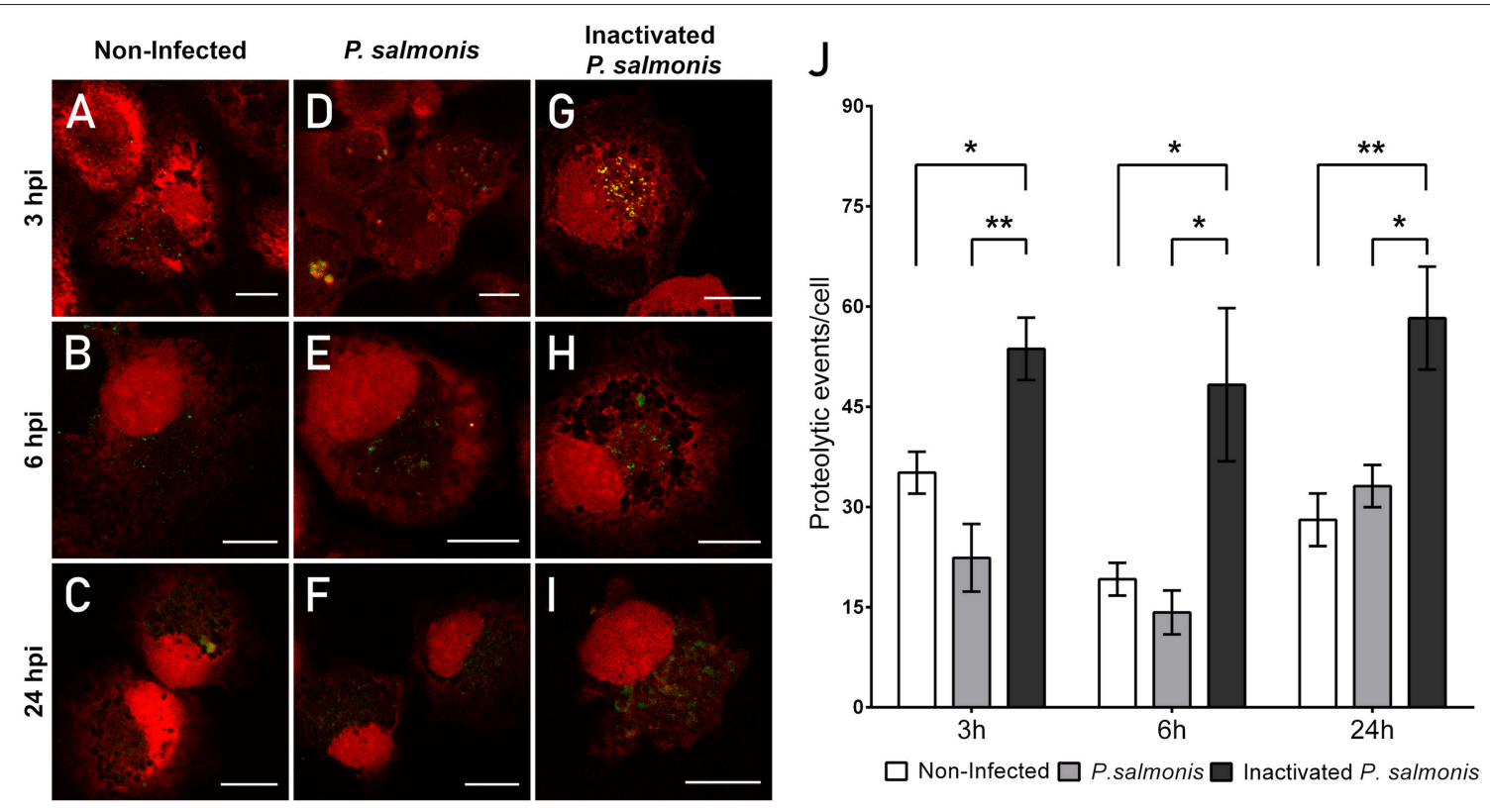

FIGURE 4 | Lysosomal functionality in macrophage-enriched cell cultures infected with $P$. salmonis. Macrophage-enriched cell cultures were infected with $P$. salmonis at a $\mathrm{MOI}$ of 10 bacteria/cell and analyzed at 3, 6, and 24 hpi. Cells were treated with the DQ-BSA ${ }^{\text {TM }}$ Green probe to stain the proteolytic focusses; the nucleus was stained with PI (red). Non-infected macrophage-enriched cell culture and incubation with inactivated P. salmonis were used as controls for each time point. (A-C) Non-infected macrophages analyzed at 3, 6, and $24 \mathrm{~h}$. Macrophage-enriched cell culture incubated with $P$. salmonis for $3 \mathrm{~h}$ (D), $6 \mathrm{~h}$ (E), and $24 \mathrm{~h}$ (F).

Macrophage-enriched cell culture incubated with inactivated P. salmonis for $3 \mathrm{~h}$ (G), $6 \mathrm{~h} \mathbf{( H )}$, and $24 \mathrm{~h}$ (I). Scale bar: $10 \mu \mathrm{m}$. (J) Quantification of proteolytic events in macrophage-enriched cell cultures infected with $P$. salmonis. Macrophage-enriched cell cultures were infected with $P$. salmonis at a MOI of 10 bacteria/cell and analyzed at 3, 6, and 24 hpi. The proteolytic events were detected using the DQ-BSA Green probe and data were quantified and normalized to the number of cells analyzed for each condition. Non-infected macrophage-enriched cell culture and incubation with inactivated $P$. salmonis were used as controls for each time point. The statistical analysis was performed through a parametric ANOVA with a Dunnett's multiple comparison test. Significant differences: ${ }^{*} p<0.05$, ${ }^{* *} p<0.01$.

damaged or misfolded proteins) and entire organelles to the lysosome (41).

Macrophages have been described as a phagocyte population that play an important role in specific and non-specific immune responses, owing to their specialized phagocytic capacity, antigen-presenting function, secretion of cytokines, and efficient antimicrobial activity $(42,43)$. Considering that the macrophages are one of the first cell types which pathogens encounter after their entry into the host, many pathogens are internalized by endocytosis or phagocytosis-intracellular pathways that culminate the degradation in the lysosomal system. In this sense, it is not surprising that some pathogens have developed intracellular immune evasion mechanisms against macrophages $(14,44,45)$. In the present study, we observed that $P$. salmonis evades host response mechanisms by reducing the lysosomal acidification and its proteolytic activity in the first hpi. Thus, this pathogen is able to reside in macrophage-enriched cell cultures for 24 hpi and replicate for $\geq 120$ hpi (Figure 1).

Macrophage infection is a common strategy adopted by several intracellular pathogens to colonize and spread into their hosts. This is achieved through interference with normal cell signaling and disruption of the normal responses triggered to eliminate foreign invaders, such as the lysosomal system of degradation. Interference with this system allows pathogen survival and evasion of the host immune response (11, 18, 45). In mammals, a good example is L. pneumophila, which presents mechanisms to recruit and manipulate the transport of the phagosome using $>300$ bacterial genes encoding different proteins (termed effectors) that are secreted from the bacteria to the host cell $(46,47)$. One of these mechanisms is associated with the prevention of phagosome acidification through the recruitment of Rab1 to the phagosome (48). Acidification of the phagosome is necessary for efficient lysosomal fusion and function. L. pneumophila employs several mechanisms to recruit Rab1 to the Legionella-containing vacuole (LCV). Multiple Dot/Icm secreted factors, such as DrrA/SidM, SidD, and LepB function together to manipulate the localization of Rab1 to the LCV, thus cycling the host protein between the active (anchored to the LCV) and inactive states. On the other hand, L. pneumophila also manipulates Rab1 independently of recruitment to the LCV through the action of SidC/SdcA, LidA, and AnkX. This redundancy in the mechanisms indicates that Rab1 manipulation by L. pneumophila is extremely important for the intracellular survival of this pathogen (49). The molecular mechanisms involved in host response evasion which are modulated by $P$. salmonis remain to be elucidated. 
In fish, relatively few pathogens have been reported to resist degradation and replicate within macrophages. Virulent Edwarsiella tarda is capable of survival and replication in head kidney phagocytes of blue gourami (Trichogaster trichopterus) at least by $6.5 \mathrm{hpi}$, where induces low levels of reactive oxygen intermediates by infected phagocytes $(14,50)$. Photobacterium damselae subsp. piscicida is an intracellular pathogen that can survive and multiply within macrophages of hybrid striped bass, via inhibition of the phagosome-lysosome fusion and replication in vacuoles at least by 18 hpi (Morone saxatilis $\times$ white bass M. chrysops) (14, 51). Similarly, Mycobacterium spp. have been found both intact and partially degraded inside phagolysosomes of rainbow trout macrophages, suggesting that some degree of inhibition of the phagosome-lysosome fusion occurs to favor bacterial survival $(14,52)$. Renibacterium salmoninarum survives within macrophages even at $4 \mathrm{dpi}$, suggesting that this bacterium escapes from the phagosome and resides in a bacteria-containing vesicle with a tightly apposed membrane by interfering with the macrophage-killing pathways $(14,53,54)$.

These examples reflect the possibility that in fish, like in mammals, certain pathogens have developed evasion mechanisms against macrophages as part of their life-cycle, using the cell as a shield against cell-mediated and humoral immune responses (44). However, the mechanism used by fish pathogens to resist the macrophage killing-mechanism is currently not understood and requires investigation. In the present study, we detected viable $P$. salmonis in macrophageenriched cell cultures after $5 \mathrm{dpi}$ and observed a two-fold increase in its detection using qPCR. These results suggest bacterial survival and replication (Figure 2). The increase in bacterial load detected through qPCR at 120 hpi was inconsistent with the FITC-fluorescence intensity observed at the same time points (Figure 1). However, this discrepancy is probably due to a decline in FITC fluorescence, which has been reported to decrease during prolonged incubation times (55). However, this approach allows us to observe P. salmonis in the infected cells. These results are consistent with those previously observed in macrophages obtained from rainbow trout head kidneys-in which concurrent destruction and replication were observed at 5 dpi-implying that $P$. salmonis is able to survive and reproduce in functional macrophages (14).

An analysis performed to characterize the function of the lysosome showed that the number of lysosomes in macrophage-enriched cell cultures infected with $P$. salmonis (Figure 3) does not increase in the first $24 \mathrm{hpi}$. This evidence suggests a delayed response, which is further supported by evidence showing that incubation with inactivated P. salmonis resulted in an increase in the number of lysosomes by more than three-fold $6 \mathrm{~h}$ post-incubation. An increase in lysosome biogenesis/function has been reported to contribute to limiting intracellular macrophage infection in mice (56). Lysosomes must maintain an acidic luminal $\mathrm{pH}$ to activate hydrolytic enzymes and degrade internalized macromolecules (57). Thus, lysosomal acidification is a key environmental mechanism for the correct function of this organelle. Analysis of the lysosomal $\mathrm{pH}$ following infection of macrophage-enriched cell cultures with $P$. salmonis showed that at $3 \mathrm{hpi}$, approximately $70 \%$ of lysosomes presented an acidic $\mathrm{pH}$. Interestingly, this percentage diminished at 6 and $24 \mathrm{hpi}$ to values $<40 \%$. Conversely, incubation with inactivated P. salmonis showed an acidic $\mathrm{pH}$ in $>75 \%$ of lysosomes, reflecting that macrophage-like cells respond to the appropriate stimulus. Previous studies have reported early lysosomal acidification in macrophage-enriched cell cultures infected by $P$. salmonis at $2 \mathrm{hpi}$, suggesting that the acidification may be the signal that induces the intracellular overexpression of the $P$. salmonis dot/icm genes (11). This dot/icm gene expression may be responsible for the observed decrease in the number of lysosomes with an acidic $\mathrm{pH}$, as previously described in $L$. pneumophila $(48,49)$. The functional consequence of the disruption of lysosomal acidification is a poor hydrolytic activity. In the present study, this was observed by the low levels of degradation of $\mathrm{DQ}^{\mathrm{TM}}$ Green BSA in macrophage-like cells infected by $P$. salmonis compared with those observed in cells incubated with inactivated $P$. salmonis (Figure 4). However, expression or functional analyses are required to identify which part of the mechanism of assembly or function is targeted by $P$. salmonis during its interference with the lysosomal response.

Collectively, the results showed that infection of Atlantic salmon macrophages with $P$. salmonis induced a limited lysosomal response in the first hpi, which may correspond to a strategy of immune evasion that has not been previously reported. Previous studies have described that $P$. salmonis does not reach lysosomal compartments in which TIVBSS plays a central role $(11,14)$. Currently, there is limited knowledge available regarding the pathogenetic mechanisms of $P$. salmonis. However, the similarities observed with the phylogenetically closely related bacteria L. pneumophila (58) suggest that $P$. salmonis may use a similar mechanism of pathogenesis to those of L. pneumophila. Both bacteria target macrophages and disruption of the lysosomal degradation pathways appears to be a hallmark of their infection.

\section{DATA AVAILABILITY}

All datasets generated for this study are included in the manuscript and/or the supplementary files.

\section{AUTHOR CONTRIBUTIONS}

DP-S and JM-R performed most of the experiments, analyzed the data, prepared the figures, and contributed to the writing of this manuscript. ST, DA, AE, VS-H, BB, and VI performed the experiments. JV, EV-V, AS, and ES reviewed this manuscript. SR-C conceived and supervised the study. SR-C and FR-L wrote this manuscript.

\section{FUNDING}

This work was financially supported by FONDECYT Iniciación 11150807, Start-Up UMayor 101205, CORFO 13CTI-21527, UMayor-Ph.D. fellowships to DP-S and CONICYT-BCH Postdoctoral fellowship to EV-V. 


\section{SUPPLEMENTARY MATERIAL}

The Supplementary Material for this article can be found online at: https://www.frontiersin.org/articles/10.3389/fimmu. 2019.00434/full\#supplementary-material

Supplementary Figure 1 | Viability assay of FITC stained $P$. salmonis.

Non-stained $P$. salmonis and FITC stained $P$. salmonis were plated on enriched

\section{REFERENCES}

1. Fryer JL, Hedrick RP. Piscirickettsia salmonis: a gram-negative intracellular bacterial pathogen of fish. J Fish Dis. (2003) 26:251-62. doi: 10.1046/j.1365-2761.2003.00460.x

2. Gaggero A, Castro H, Sandino AM. First isolation of Piscirickettsia salmonis from coho salmon, Oncorhynchus kisutch (Walbaum), and rainbow trout, Oncorhynchus mykiss (Walbaum), during the freshwater stage of their life cycle. J Fish Dis. (1995) 18:277-9. doi: 10.1111/j.1365-2761.1995.tb 00303.x

3. Branson EJ, Nieto-Diaz Muñoz D. Description of a new disease condition occurring in farmed coho salmon, Oncorhynchus kisutch (Walbaum), in South America. J Fish Dis. (1991) 14:147-56.

4. Cvitanich JD, Garate N, Smith CE. The isolation of a rickettsial-like organism causing disease and mortality in Chilean salmonids and its confirmation by Koch's postulate. J Fish Dis. (1991) 14:121-45.

5. Mauel MJ, Miller DL. Piscirickettsiosis and piscirickettsiosis-like infections in fish: a review. Vet Microbiol. (2002). 87:279-89. doi: 10.1016/S0378-1135(02)00085-8

6. Colquhoun DJ. Other bacterial infections of fish. In: Hjeltnes B, BangJensen B, Bornø G, Haukaas A, Walde CS, editors. The Health Situation in Norwegian Aquaculture 2017. Report 1b-2018 Annual Summary of Fish Health in Norway. Oslo: Norwegian Veterinary Institute (2018). p. 58-9.

7. Kidder GW, Montgomery CW. SERNAPESCA, Informe Sanitario Acuícola año 2017. Valparaíso: Departamento de Salud Animal, Subdirección de Acuicultura, Servicio Nacional de Pesca y Acuicultura (2018).

8. Marshall SH, Conejeros P, Zahr M, Olivares J, Gómez F, Cataldo P., et al. Immunological characterization of a bacterial protein isolated from salmonid fish naturally infected with Piscirickettsia salmonis. Vaccine. (2007) 25:2095102. doi: 10.1016/j.vaccine.2006.11.035

9. SERNAPESCA, Informe Sanitario Acuícola año 2012. Valparaíso: Unidad de Salud Animal, Subdirección de Acuicultura, Servicio Nacional de Pesca y Acuicultura, Servicio Nacional de Pesca y Acuicultura, Gobierno de Chile (2013).

10. Aqua. Sernapesca: El SRS Sigue Siendo el Mayor Problema Sanitario Que Enfrenta la Salmoniculttura. (2012) Available online at: http://www.aqua.cl/ 2012/11/23/sernapesca-el-srs-sigue-siendo-el-mayor-problema-sanitarioque-enfrenta-la-salmoniculttura/\#

11. Gómez FA, Tobar JA, Henríquez V, Sola M, Altamirano C, Marshall SH. Evidence of the presence of a functional Dot/Icm type IV-B secretion system in the fish bacterial pathogen Piscirickettsia salmonis. PLoS ONE. (2013) 8:e54934. doi: 10.1371/journal.pone.0054934

12. Gómez FA, Cárdenas C, Henríquez V, Marshall SH. Characterization of a functional toxin-antitoxin module in the genome of the fish pathogen Piscirickettsia salmonis. FEMS Microbiol Lett. (2011) 317:83-92. doi: 10.1111/j.1574-6968.2011.02218.x

13. Rojas V, Galanti N, Bols NC, Marshall SH. Productive infection of Piscirickettsia salmonis in macrophages and monocyte-like cells from rainbow trout, a possible survival strategy. J Cell Biochem. (2009) 108:631-7. doi: $10.1002 /$ jcb. 22295

14. McCarthy UM, Bron JE, Brown L, Pourahmad F, Bricknell IR, Thompson KD., et al. Survival and replication of Piscirickettsia salmonis in rainbow trout head kidney macrophages. Fish Shellfish Immunol. (2008) 25:477-84. doi: 10.1016/j.fsi.2008.07.005

15. Álvarez CA, Gomez FA, Mercado L, Ramírez R, Marshall SH. Piscirickettsia salmonis imbalances the innate immune response to succeed in a productive blood agar. Confirmation that identity of colonies correspond to $P$. salmonis was carried out by specific detection of $16 \mathrm{~S}$ rDNA by real time PCR. (A) FITC-stained $P$. salmonis plated on enriched blood agar. (B) Melt curve of the gene amplification obtained by real time PCR from a single colonies of FITC stained $P$. salmonis (red lines) and positive control (gray lines). (C) P. salmonis plated on enriched blood agar. (D) Melt curve of the gene amplification obtained by real time PCR from a single colonies of $P$. salmonis (red lines) and positive control (gray lines).

infection in a salmonid cell line model. PLoS ONE. (2016) 11:e0163943. doi: 10.1371/journal.pone.0163943

16. Kum C, Sekkin S. The immune system drugs in fish: immune function, immunoassay, drugs. In: Dogu FAAZ, editor. Recent Advances In Fish Farms. Rijekap: Intech open science (2011). p. 169-216. doi: 10.5772/26869

17. Aderem A, Underhill DM. Mechanisms of phagocytosis in macrophages. Annu Rev Immunol. (1999) 17:593-623. doi: 10.1146/annurev.immunol.17.1.593

18. Rosenberger CM, Finlay BB. Phagocyte sabotage: disruption of macrophage signalling by bacterial pathogens. Nat Rev Mol Cell Biol. (2003) 4:385-96. doi: 10.1038/nrm1104

19. Gray MA, Choy CH, Dayam RM, Ospina-Escobar E, Somerville A, Xiao $\mathrm{X}$., et al. Phagocytosis enhances lysosomal and bactericidal properties by activating the transcription factor TFEB. Curr Biol. (2016) 26:1955-64. doi: 10.1016/j.cub.2016.05.070

20. Ip WK, Sokolovska A, Charriere GM, Boyer L, Dejardin S, Cappillino MP. et al. Phagocytosis and phagosome acidification are required for pathogen processing and MyD88-dependent responses to Staphylococcus aureus. J Immunol. (2010) 184:7071-81. doi: 10.4049/jimmunol.1000110

21. Diacovich L, Gorvel JP. Bacterial manipulation of innate immunity to promote infection. Nat Rev Microbiol. (2010) 8:117-28. doi: $10.1038 /$ nrmicro2295

22. Flannagan RS, Cosío G, Grinstein S. Antimicrobial mechanisms of phagocytes and bacterial evasion strategies. Nat Rev Microbiol. (2009) 7:355-66. doi: $10.1038 /$ nrmicro 2128

23. Vincent CD, Friedman JR, Jeong KC, Buford EC, Miller JL, Vogel JP. Identification of the core transmembrane complex of the Legionella Dot/Icm type IV secretion system. Mol Microbiol. (2006) 62:1278-91. doi: 10.1111/j.1365-2958.2006.05446.x

24. Segal G, Feldman M, Zusman T. The Icm/Dot type-IV secretion systems of Legionella pneumophila and Coxiella burnetii. FEMS Microbiol Rev. (2005) 29:65-81. doi: 10.1016/j.femsre.2004.07.001

25. McDonough JA, Newton HJ, Roy CR. Coxiella burnetii secretion systems. Adv Exp Med Biol. (2012) 984:171-97. doi: 10.1007/978-94-007-4315-1_9

26. Bruns H, Stegelmann F, Fabri M, Döhner K, van Zandbergen G, Wagner M., et al. Neumeister B. Phagosomal acidification is not a prerequisite for intracellular multiplication of Legionella pneumophila in human monocytes. J Infect Dis. (2004) 189:1610-4. doi: 10.1086/382894

27. Roy CR, Kagan JC. Evasion of Phagosome Lysosome Fusion and Establishment of a Replicative Organelle by the Intracellular Pathogen Legionella Pneumophila. Madame Curie Bioscience Database. Austin: Landes Bioscience (2013). Avaialble online at: https://www.ncbi.nlm.nih.gov/books/NBK6111/

28. Braun-Nesje R, Bertheussen K, KaplanG, Seljelid R. Salmonid macrophages: separation, in vitro culture and characterization. J Fish Dis. (1981) 4:141-51. doi: 10.1111/j.1365-2761.1981.tb01118.x

29. Fryer JL, Lannan CN, Giovannoni SJ, Wood ND. Piscirickettsia salmonis gen. nov., sp. nov., the causative agent of an epizootic disease in salmonid fishes. Int J Syst Bacteriol. (1992) 42:120-6.

30. Henríquez M, González E, Marshall SH, Henríquez V, Gómez FA, Martínez I, et al. A novel liquid medium for the efficient growth of the salmonid pathogen Piscirickettsia salmonis and optimization of culture conditions. PLoS ONE. (2013) 8:e71830. doi: 10.1371/journal.pone.0071830

31. Karatas S, Mikalsen J, Steinum TM, Taksdal T, Bordevik M, Colquhoun DJ. Real time PCR detection of Piscirickettsia salmonis from formalinfixed paraffin-embedded tissues. J Fish Dis. (2008) 31:747-53. doi: 10.1111/j.1365-2761.2008.00948.x 
32. Mauel MJ, Ware C, Smith PA. Culture of Piscirickettsia salmonis on enriched blood agar. J Vet Diagn Invest. (2008) 20:213-4. doi: $10.1177 / 104063870802000211$

33. Schindelin J, Arganda-Carreras I, Frise E, Kaynig V, Longair M, Pietzsch T., et al. Fiji: an open-source platform for biological-image analysis. Nat Methods. (2012) 9:676-82. doi: 10.1038/nmeth.2019

34. Rodríguez-Tirado C, Maisey K, Rodríguez FE, Reyes-Cerpa S, Reyes-López FE, Imarai M. Neisseria gonorrhoeae induced disruption of cell junction complexes in epithelial cells of the human genital tract. Microbes Infect. (2012) 14:290-300. doi: 10.1016/j.micinf.2011.11.002

35. Imarai M, Candia E, Rodriguez-Tirado C, Tognarelli J, Pardo M, Pérez T., et al. Regulatory $\mathrm{T}$ cells are locally induced during intravaginal infection of mice with Neisseria gonorrhoeae. Infect Immun. (2008) 76:5456-65. doi: 10.1128/IAI.00552-08

36. Fast MD, Tse B, Boyd JM, Johnson SC. Mutations in the Aeromonas salmonicida subsp. salmonicida type III secretion system affect Atlantic salmon leucocyte activation and downstream immune responses. Fish Shellfish Immunol. (2009) 27:721-8. doi: 10.1016/j.fsi.2009.09.009

37. Wang MX, Cheng XY, Jin M, Cao YL, Yang YP, Wang JD., et al. TNF compromises lysosome acidification and reduces alpha-synuclein degradation via autophagy in dopaminergic cells. Exp Neurol. (2015) 271:112-21. doi: 10.1016/j.expneurol.2015.05.008

38. Marwaha R, Sharma M. DQ-Red BSA trafficking assay in cultured cells to assess cargo delivery to lysosomes. Bio Protoc. (2017) 7:e2571. doi: 10.21769/BioProtoc.2571

39. Frost LS, Dhingra A, Reyes-Reveles J, Boesze-Battaglia K. The use of DQ-BSA to monitor the turnover of autophagy-associated cargo. Methods Enzymol. (2017) 587:43-54. doi: 10.1016/bs.mie.2016.09.052

40. Russell DG, Vanderven BC, Glennie S, Mwandumba H, Heyderman RS. The macrophage marches on its phagosome: dynamic assays of phagosome function. Nat Rev Immunol. (2009) 9:594-600. doi: 10.1038/nri2591

41. Perera RM, Zoncu R. The lysosome as a regulatory hub. Annu Rev Cell Dev Biol. (2016) 32:223-253. doi: 10.1146/annurev-cellbio-111315-125125

42. Neumann NF, Stafford JL, Barreda D, Ainsworth AJ, Belosevic M. Antimicrobial mechanisms of fish phagocytes and their role in host defense. Dev Comp Immunol. (2001) 25:807-25. doi: 10.1016/S0145-305X(01)00037-4

43. Dalmo RA, Ingebrigtsen K, Bøgwald J. Non-specific defence mechanisms in fish, with particular reference to the reticuloendothelial system (RES). J Fish Dis. (1997) 20:241-73. doi: 10.1046/j.1365-2761.1997.00302.x

44. Kaufmann SH. Immunity to intracellular bacteria. Annu Rev Immunol. (1993) 11:129-63.

45. Di Russo Case E, Samuel JE. Contrasting lifestyles within the host cell. Microbiol Spectr. (2016) 4:1-19. doi: 10.1128/microbiolspec.VMBF-0014-2015

46. Meir A, Chetrit D, Liu L, Roy CR, Waksman G. Legionella DotM structure reveals a role in effector recruiting to the Type $4 \mathrm{~B}$ secretion system. Nat Commun. (2018). 9:507.

47. So EC, Mattheis C, Tate EW, Frankel G, Schroeder GN. Creating a customized intracellular niche: subversion of host cell signaling by Legionella type IV secretion system effectors. Can J Microbiol. (2015) 61:617-35. doi: 10.1139/cjm-2015-0166

48. Misch EA. Legionella: virulence factors and host response. Curr Opin Infect Dis. (2016) 29:280-6. doi: 10.1097/QCO.0000000000000268
49. Connor MG, Pulsifer AR, Price CT, Abu Kwaik Y, Lawrenz MB. Yersinia pestis requires host Rab1b for survival in macrophages. PLoS Pathog. (2015) 11:e1005241. doi: 10.1371/journal.ppat.1005241

50. Srinivasa Rao PS, Lim TM, Leung KY. Opsonized virulent Edwardsiella tarda strains are able to adhere to and survive and replicate within fish phagocytes but fail to stimulate reactive oxygen intermediates. Infect Immun. (2001) 69:5689-97. doi: 10.1128/IAI.69.9.56895697.2001

51. Elkamel A, Hawke JP, Henk WG, Thune RL. Photobacterium damselae subsp. piscicida is capable of replicating in hybrid striped bass macrophages. J Aquat Anim Health. (2003) 15:175-83. doi: 10.1577/H03-006

52. Chen SC, Adams A, Thompson KD, Richards RH. Electron microscope studies of the in vitro phagocytosis of Mycobacterium spp. by rainbow trout Oncorhynchus mykiss head kidney macrophages. Dis Aquat Organ. (1998) 32:99-110.

53. Gutenberger SK, Duimstra JR, Rohovec JS, Fryer JL. Intracellular survival of Renibacterium salmoninarum in trout mononuclear phagocytes. Dis Aquat Organ. (1997) 28:93-106. doi: 10.3354/dao028093

54. Grayson TH, Cooper LF, Wrathmell AB, Roper J, Evenden AJ, Gilpin ML. Host responses to Renibacterium salmoninarum and specific components of the pathogen reveal the mechanisms of immune suppression and activation. Immunology. (2002) 106:273-83. doi: 10.1046/j.1365-2567.2002. 01420.x

55. Steele-Mortimer O, Méresse S, Gorvel JP, Toh BH, Finlay BB. Biogenesis of Salmonella typhimurium-containing vacuoles in epithelial cells involves interactions with the early endocytic pathway. Cell Microbiol. (1999) 1:33-49.

56. Vural A, Al-Khodor S, Cheung GY, Shi CS, Srinivasan L, McQuiston TJ, et al. Activator of G-Protein signaling 3-induced lysosomal biogenesis limits macrophage intracellular bacterial infection. J Immunol. (2016) 196:846-56. doi: 10.4049/jimmunol.1501595

57. Ishida Y, Nayak S, Mindell JA, Grabe M. A model of lysosomal pH regulation. J Gen Physiol. (2013) 141:705-20. doi: 10.1085/jgp.201210930

58. Mauel MJ, Giovannoni SJ, Fryer JL.Mauel MJ, Giovannoni SJ, Fryer JL. Phylogenetic analysis of Piscirickettsia salmonis by 16 S, internal transcribed spacer (ITS) and 23S ribosomal DNA sequencing. Dis Aquat Organ. (1999) 35:115-23

Conflict of Interest Statement: JM-R, AS, and ES were employed by company Consorcio de Sanidad Acuícola Ictio Biotechnologies S.A.

The remaining authors declare that the research was conducted in the absence of any commercial or financial relationships that could be construed as a potential conflict of interest.

Copyright (C) 2019 Pérez-Stuardo, Morales-Reyes, Tapia, Ahumada, Espinoza, Soto-Herrera, Brianson, Ibaceta, Sandino, Spencer, Vallejos-Vidal, Reyes-López, Valdés and Reyes-Cerpa. This is an open-access article distributed under the terms of the Creative Commons Attribution License (CC BY). The use, distribution or reproduction in other forums is permitted, provided the original author(s) and the copyright owner(s) are credited and that the original publication in this journal is cited, in accordance with accepted academic practice. No use, distribution or reproduction is permitted which does not comply with these terms. 